\title{
Dieback Reality of Apple Trees Resulting from Soil-Borne Fungal Pathogens in South Korea from 2016 to 2019
}

*Corresponding author

Tel: $+82-43-220-6561$

Fax: +82-43-220-6565

E-mail: darkhorses@korea.kr

\author{
Sung-Hee Lee ${ }^{1 *}$, Hyunman Shin ${ }^{1}$, Who-Bong Chang ${ }^{1}$, Kyoung-Yul Ryu ${ }^{2}$, \\ Heung Tae $\mathrm{Kim}^{3}$, Byeongjin $\mathrm{Cha}^{3}$, and Jae-Soon $\mathrm{Cha}^{3}$ \\ 'Bureau of Research \& Development, Chungcheongbuk-do Agricultural Research and Extension Services, \\ Cheongju 28130, Korea \\ ${ }^{2}$ Department of Agro-food Safety and Crop Protection, National Institute of Agricultural Sciences, Rural \\ Development Administration, Wanju 55365, Korea \\ ${ }^{3}$ Department of Plant Medicine, Chungbuk National University, Cheongju 28644, Korea
}

Received May 19, 2020

Revised June 22, 2020

Accepted June 30, 2020

\begin{abstract}
Recently, the severe dieback of apple trees resulting from soil-borne diseases has occurred in South Korea. The casual agents of dieback were surveyed on 74 apple orchards that had been damaged nationwide in 2016-2019. The number of apple orchards affected alone by Phytophthora rot, violet root rot, and white root rot was 31,34, and 3, respectively. Also, the total number of mixed infection orchards was 6 . Out of 9,112 apple trees affected by dieback, the trees damaged by Phytophthora rot, violet root rot, and white root rot were 3,332, 3,831, and 44, respectively. Moreover, the total number of mixed infection apple trees was 1,905. The provinces mainly affected were Gyeongnam, Gyeongbuk, Chungbuk, and Jeonbuk. The survey on these infected apple orchards will be available to form management strategy for the dieback that had been increased by soil-borne fungal pathogens.
\end{abstract}

Keywords: Apple tree, Dieback, Root rot, Soil-borne diseases

\section{Introduction}

Recently, the economic loss of apple growers throughout the country has become serious, sustained at about $\$ 2$ million per year, owing to the dieback resulting from soil-borne fungal pathogens such as Phytophthora cactorum, Helicobasidium mompa, and Rosellinia necatrix. In apple trees, Phytophthora cactorum causes the rot of root, crown, and stem. Also, Helicobasidium mompa and Rosellinia necatrix results in violet root rot and white root rot, respectively (Lee et al., 2016; Rural Development Administration, National Institute of Agricultural Science and Technology, 1993; The Korean Society of

Research in Plant Disease

pISSN 1598-2262, elSSN 2233-9191

www.online-rpd.org
Plant Pathology, 2009).

The symptoms caused by soil-borne diseases induce the reduction of the number of leaves and leaf area with the increase of vacant branches due to poor growth and fruit setting, and finally result in dieback (Lee et al., 1995; Lee et al., 2009; Lee et al., 2016). These symptoms are likely to be confused with physiological disorders, which make it difficult to diagnose the causes quickly and accurately (Lee et al., 1995). Nonetheless, Lee et al. (2016) reported a method to diagnose the causes of dieback resulting from soil-borne diseases at apple orchards.

Meanwhile, at the time when the symptoms were already marked and the infection had spread, the rots became so severely damaged that apple growers lost the time to control the situation, and eventually faced the dieback of apple trees (Lee et al., 2009). Furthermore, the apple growers could have 
had a great difficulty because the diseases spread through the soil continuously if the infected roots are not completely removed (Lee et al., 2016).

The survey on the occurrence of soil-borne diseases at the apple orchards across the country (Lee et al., 1995) has been conducted in the main apple production sites in South Korea. As a part of the survey on major apple diseases which had occurred in 1992-2000, the type and extent of diseases affecting the roots of apple trees were reported (Lee et al., 2006). Most recently, Lee et al. (2016) have reported that the number of apple trees with dieback symptom was 4,000 in Chungbuk province from 2013 to 2015, and among them 3,350 were damaged by soil-borne diseases. Therefore, this survey was carried out to ascertain the reality of the dieback damage by soil-borne fungal pathogens which had occurred at apple orchards nationwide in 2016-2019.

\section{Materials and Methods}

This survey was conducted by phone call inquiry consulting the 74 apple growers who had faced the dieback due to soil-borne diseases in 7 provinces across the country in 2016-2019. With the dieback symptoms and signs inquired from every damaged apple grower, its causes were known by a previously designed diagnostic method (Lee et al., 2016). Using this method, Phytophthora (root, crown, and stem) rot caused by Phytophthora cactorum could be diagnosed by the rot of bark tissue at the root or grafting area, with its discoloration to dark brown color, or by the weeping of stem bark tissue in apple trees (Jee et al., 1997, 2001; Lee et al., 2016). Violet root rot induced by Helicobasidium mompa could be distinguished by the formation of reddish violet fruiting body on the grafting region (Lee et al., 1995; Lee et al., 2016). White root rot caused by Rosellinia necatrix could be characterized by the mycelia membrane formation of white fan shape (Hanlin, 1990; Lee et al., 2016; Rural Development Administration, National Institute of Agricultural Science and Technology, 1993; Sivanesan and Holliday, 1972). In addition, the survey was made on the number of surveyed trees and initial pathogenesis year (from 2015 to 2019, 2010 to 2015 , before 2010 ) in diseased orchard lot were investigated.

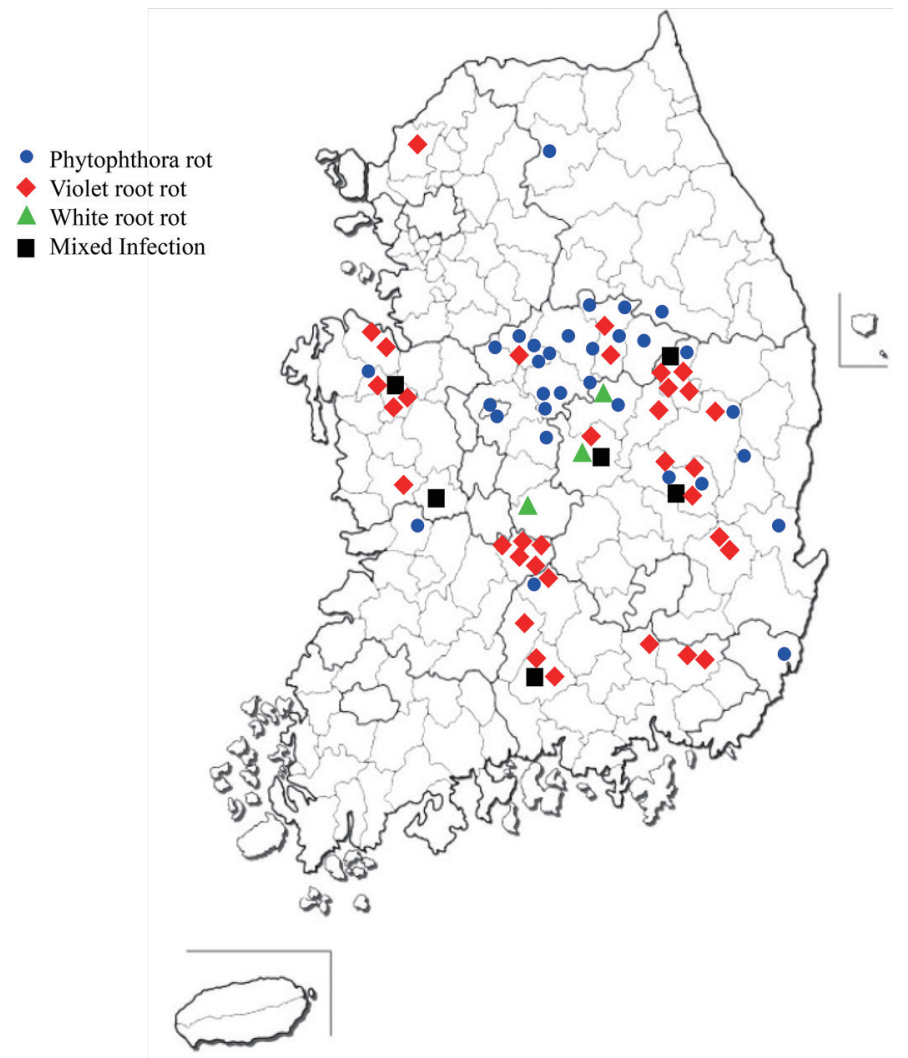

Fig. 1. Distribution map of dieback pathogenesis which occurred at the 74 apple orchards resulting from soil-borne fungal pathogens in South Korea from 2016 to 2019.

\section{Results and Discussion}

In 2016-2019, a total of 9,112 dieback trees at the 74 apple orchards that had occurred in 7 provinces are represented in the distribution map (Fig. 1). The number of apple orchards and trees infected by each province is shown in Tables 1 and 2 , respectively. And, the classification for initial pathogenesis year is shown in Table 3. Major provinces affected by the diseases were Gyeongbuk with 24 orchards (32.4\%), and Chungbuk with 22 orchards (29.7\%). On the other hand, no phone call inquiry was made in Jeonnam, which chiefly cultivates pear trees (Table 1). Thirty-one orchards (41.9\%) of 74 damaged apple orchards in total were caused by Phytophthora rot, and provinces were Chungbuk with 18 orchards (24.3\%), and Gyeongbuk with 7 orchards (9.5\%). Thirty-four orchards $(46.0 \%)$ out of them were affected by violet root rot and the main province with pathogenesis was Gyeongbuk with 12 orchards (16.2\%). Three orchards (4.1\%) were diseased by white root rot.

Meanwhile, the survey of mixed infections was made on 6 
Table 1. Number of apple orchards shown dieback symptom resulting from soil-borne fungal pathogens throughout the country

\begin{tabular}{|c|c|c|c|c|c|c|c|}
\hline \multirow{2}{*}{ Province } & \multicolumn{6}{|c|}{ No. of the apple orchard infected by soil-borne diseases } & \multirow{2}{*}{$\begin{array}{c}\text { Total no. } \\
\text { damaged } \\
\text { orchards }\end{array}$} \\
\hline & PR & VRR & WRR & PR+VRR & VRR+WRR & PR+VRR+WRR & \\
\hline Gyeonggi & ND & $1(1.4)$ & ND & ND & ND & ND & $1(1.4)$ \\
\hline Gangwon & $2(2.7)$ & ND & ND & ND & ND & ND & $2(2.7)$ \\
\hline Chungbuk & $18(24.3)$ & $3(4.1)$ & $1(1.4)$ & ND & ND & ND & $22(29.7)$ \\
\hline Chungnam & $1(1.4)$ & $6(8.1)$ & ND & $1(1.4)$ & ND & $1(1.4)$ & $9(12.2)$ \\
\hline Jeonbuk & $1(1.4)$ & $5(6.8)$ & ND & ND & ND & ND & $6(8.1)$ \\
\hline Jeonnam & ND & ND & ND & ND & ND & ND & ND \\
\hline Gyeongbuk & $7(9.5)$ & $12(16.2)$ & $2(2.7)$ & $1(1.4)$ & $1(1.4)$ & $1(1.4)$ & $24(32.4)$ \\
\hline Gyeongnam & $2(2.7)$ & $7(9.5)$ & ND & ND & $1(1.4)$ & ND & $10(13.5)$ \\
\hline Total no. of damaged orchards & $31(41.9)$ & $34(46.0)$ & $3(4.1)$ & $2(2.7)$ & $2(2.7)$ & $2(2.7)$ & $74(100)$ \\
\hline
\end{tabular}

Values are presented as number (\%).

PR, Phytophthora (root, crown, stem) rot by Phytophthora sp.; VRR, violet root rot by Helicobasidium sp.; WRR, white root rot by Rosellinia sp.; ND, no data.

${ }^{\mathrm{a}} \%$ : (Total of damaged orchards/74 apple orchards diseased) $\times 100$.

Table 2. Number of apple trees shown dieback symptom resulting from soil-borne fungal pathogens all of the nation

\begin{tabular}{|c|c|c|c|c|c|c|c|c|}
\hline \multirow{2}{*}{ Province } & \multirow{2}{*}{$\begin{array}{c}\text { No. of } \\
\text { surveyed } \\
\text { apple trees }\end{array}$} & \multicolumn{6}{|c|}{ No. of apple trees infected by soil-borne diseases } & \multirow{2}{*}{$\begin{array}{c}\text { Total no. of } \\
\text { damaged } \\
\text { trees }^{\mathrm{a}}\end{array}$} \\
\hline & & PR & VRR & WRR & PR+VRR & VRR+WRR & PR+VRR+WRR & \\
\hline Gyeonggi & 480 & ND & $7(1.5)$ & ND & ND & ND & ND & $7(1.5)$ \\
\hline Gangwon & 1,520 & $55(3.6)$ & ND & ND & ND & ND & ND & $55(3.6)$ \\
\hline Chungbuk & 7,130 & $1,434(20.1)$ & $235(3.3)$ & $6(0.1)$ & ND & ND & ND & $1,675(23.5)$ \\
\hline Chungnam & 10,700 & $14(0.1)$ & $335(3.1)$ & ND & $250(2.3)$ & ND & $24(0.2)$ & $623(5.8)$ \\
\hline Jeonbuk & 8,400 & $1,100(13.1)$ & $440(5.2)$ & ND & ND & ND & ND & $1,540(18.3)$ \\
\hline Jeonnam & ND & ND & ND & ND & ND & ND & ND & ND \\
\hline Gyeongbuk & 27,280 & 712 (2.6) & $958(3.5)$ & $38(0.1)$ & $550(2.0)$ & $51(0.2)$ & $30(0.1)$ & 2,339 (8.6) \\
\hline Gyeongnam & 12,320 & $17(0.1)$ & $1,856(15.1)$ & ND & ND & $1,000(8.1)$ & ND & $2,873(23.3)$ \\
\hline $\begin{array}{l}\text { Total no. of } \\
\text { damaged trees }\end{array}$ & 67,830 & $3,332(4.9)$ & $3,831(5.7)$ & $44(0.1)$ & $800(1.2)$ & 1,051 (1.6) & $54(0.1)$ & $9,112(13.4)$ \\
\hline
\end{tabular}

Values are presented as number (\%).

PR, Phytophthora (root, crown, stem) rot by Phytophthora sp.; VRR, violet root rot by Helicobasidium sp.; WRR, white root rot by Rosellinia sp.; ND, no data.

${ }^{\mathrm{a}} \%$ : (Total of damaged trees/No. of surveyed apple trees) $\times 100$.

among 74 orchards. The mixed infection of both Phytophthora rot and violet root rot occurred at one orchard in each of the Chungnam and Gyeongbuk province. That of both violet root rot and white root rot occurred at orchard in each of the Gyeongbuk and Gyeongnam province. The mixed infection caused by all the diseases such as Phytophthora rot, violet root rot, and white root rot occurred at 1 orchard in Chungnam and Gyeongbuk province each (Table 1). This survey indicates that at least $87.9 \%$ of the apple orchards that had shown dieback symptom was mainly caused by Phytophthora and Helicobasidium. It also reveals that the mixed infection such as Phytophthora rot, violet root rot, and 
Table 3. Initial pathogenesis year of soil-borne diseases for each damaged apple orchard across the country

\begin{tabular}{|c|c|c|c|c|c|c|c|c|c|c|c|c|c|c|c|c|c|c|}
\hline \multirow{3}{*}{ Province } & \multicolumn{18}{|c|}{ Initial pathogenesis year of soil-borne diseases } \\
\hline & \multicolumn{3}{|c|}{ PR } & \multicolumn{3}{|c|}{ VRR } & \multicolumn{3}{|c|}{ WRR } & \multicolumn{3}{|c|}{ PR+VRR } & \multicolumn{3}{|c|}{ VRR+WRR } & \multicolumn{3}{|c|}{ PR+VRR+WRR } \\
\hline & $\geq \geq^{\prime} 15$ & '15-'10 & $<10$ & $\geq 15$ & '15-'10 & $<10$ & $\geq 15$ & '15-'10 & $<10$ & $\geq \geq^{\prime} 15$ & '15-'10 & $<10$ & $\geq \geq^{\prime} 15$ & '15-'10 & $<10$ & $\geq{ }^{\prime} 15$ & '15-'10 & $<10$ \\
\hline Gyeonggi & & ND & & 1 & 0 & 0 & & ND & & & ND & & & ND & & & ND & \\
\hline Gangwon & 0 & 2 & 0 & & ND & & & ND & & & ND & & & ND & & & ND & \\
\hline Chungbuk & 13 & 4 & 1 & 1 & 2 & 0 & 1 & 0 & 0 & & ND & & & ND & & & ND & \\
\hline Chungnam & 1 & 0 & 0 & 2 & 3 & 1 & & ND & & 0 & 1 & 0 & & ND & & 1 & 0 & 0 \\
\hline Jeonbuk & 0 & 0 & 1 & 4 & 1 & 0 & & ND & & & ND & & & ND & & & ND & \\
\hline Jeonnam & & ND & & & ND & & & ND & & & ND & & & ND & & & ND & \\
\hline Gyeongbuk & 6 & 1 & 0 & 2 & 9 & 1 & 2 & 0 & 0 & 1 & 0 & 0 & 1 & 0 & 0 & 1 & 0 & 0 \\
\hline Gyeongnam & 2 & 0 & 0 & 4 & 2 & 1 & & ND & & & ND & & 1 & 1 & 0 & & ND & \\
\hline Total & $\begin{array}{c}22 \\
(71.0)\end{array}$ & $\begin{array}{c}7 \\
(22.6)\end{array}$ & $\begin{array}{c}2 \\
(6.5)\end{array}$ & $\begin{array}{c}14 \\
(41.2)\end{array}$ & $\begin{array}{c}17 \\
(50.0)\end{array}$ & $\begin{array}{c}3 \\
(8.8)\end{array}$ & $\begin{array}{c}3 \\
(100)\end{array}$ & $\begin{array}{c}0 \\
(0)\end{array}$ & $\begin{array}{c}0 \\
(0)\end{array}$ & $\begin{array}{c}1 \\
(50)\end{array}$ & $\begin{array}{c}1 \\
(50)\end{array}$ & $\begin{array}{c}0 \\
(0)\end{array}$ & $\begin{array}{c}2 \\
(66.7)\end{array}$ & $\begin{array}{c}1 \\
(33.3)\end{array}$ & $\begin{array}{c}0 \\
(0)\end{array}$ & $\begin{array}{c}2 \\
(100)\end{array}$ & $\begin{array}{c}0 \\
(0)\end{array}$ & $\begin{array}{c}0 \\
(0)\end{array}$ \\
\hline
\end{tabular}

Values are presented as number (\%).

PR, Phytophthora (root, crown, stem) rot by Phytophthora sp.; VRR, violet root rot by Helicobasidium sp.; WRR, white root rot by Rosellinia sp.; ND, no data.

white root rot has occurred later.

The classification of initial pathogenesis year for each of the damaged 74 apple orchards is shown in Table 3. In Phytophthora rot, the number of apple orchards for initial pathogenesis year of 10 years and under (from 2010 to 2019) was 29 (93.6\%), including 22 (71.0\%) from 2015 to 2019, and 7 (22.6\%) from 2010 to 2015 . For white root rot, that for initial pathogenesis year of 10 years and under was 31 (91.2\%), including 14 (41.2\%) from 2015 to 2019 , and 17 (50.0\%) from 2010 to 2015. Regarding white root rot, that for initial pathogenesis year of 5 years (from 2015 to 2019) and under was 3 (100\%). In mixed infection, most of initial pathogenesis year was 10 years and under as shown in Table 3.

The number of diseased apple trees by each province is shown in Table 2. A total of surveyed apple trees were 67,830, and the number of dieback trees among them was 9,112 (13.4\%). The main pathogenesis provinces were Gyeongnam with 2,873 (23.3\%) among 12,320, Gyeongbuk with 2,339 (8.6\%) among 27,280, Chungbuk with 1,675 (23.5\%) among 7,130 , and Jeonbuk with 1,540 (18.3\%) dieback trees among 8,400 surveyed trees. The pathogenesis of 3,332 (4.9\%) dieback trees among 67,830 surveyed apple trees resulted from Phytophthora rot, and its main provinces under damaged were Chungbuk with 1,434 (20.1\%) among 7,130, and Jeonbuk with 1,100 (13.1\%) among 8,400 surveyed trees. Three thousand eight hundred thirty-one (5.7\%) among them were caused by violet root rot, and its major provinces were Gyeongnam with 1,856 (15.1\%) among 12,320, and Gyeongbuk with 958 (3.5\%) among 27,280. Forty-four (0.1\%) among them were caused by white root rot, and the province mainly affected was Gyeongbuk with $38(0.1 \%)$ and Chungbuk with $6(0.1 \%)$ among 27,280 and 7,130, respectively.

Meanwhile, in the case of mixed infection, 800 (1.2\%) among them were damaged by Phytophthora rot and violet root rot, Gyeonbuk with 550 (2.0\%) and Chungnam with 250 (2.3\%). One thousand fifty-one (1.6\%) among them were diseased by violet and white root rot, Gyeongnam with 1,000 (8.1\%) and Gyeongbuk with 51 (0.2\%). Fifty-four (0.1\%) among them were brought about by Phytophthora rot, violet and white root rot. The provinces mainly affected were Gyeongbuk with $30(0.1 \%)$ and Chungnam with $24(0.2 \%)$ dieback trees as in Table 2 . This survey indicates that at least $10.6 \%$ of the $9,112(13.4 \%)$ apple trees that showed dieback symptom was caused by Phytophthora rot and violet root rot. Also it reveals that the number of apple trees with mixed infection such as Phytophthora rot, violet root rot, and white root rot accounted for 1,905 (2.9\%).

Our survey for the mixed infections in apple orchard lot is the first report. The mixed infections make it more difficult to control than single infections because each diseased apple 
tree has to be made an accurate diagnosis and then applied with corresponding fungicide. Also, abuse of fungicide for the mixed infection would be not only increased the farm's cost but also led to emerge its resistant strains.

Lee et al. (1995) reported that 352 (8.1\%) apple trees had been infected by soil-borne diseases among 4,320 trees at 46 apple orchards throughout the country (5 provinces) in 1991-1993. The number of these trees infected by Phytophthora rot was $9(0.2 \%)$, that of by violet root rot was $220(5.1 \%)$, and that of by white root rot was $118(2.5 \%)$. The number of apple trees infected in Jeonnam was the highest with 163 (45.3\%) at 3 apple orchards, followed by Gyeongbuk with $123(38.5 \%)$ at 23 apple orchards, Chungnam with 32 (13.2\%) at 6 apple orchards, Chungbuk with $30(9.3 \%)$ at 11 apple orchards, and Jeonbuk with 14 (3.9\%) at 3 apple orchards. This survey was carried out on a larger number of apple orchard and diseased apple trees which were more than that in the report above. The number of apple trees diseased by Phytophthora rot increased significantly to 3,332 at 31 apple orchards in comparison with the previous data (Lee et al., 1995). The number of infected trees by violet root rot showed a significant increase by 3,831 at 34 apple orchards, while that of by white root rot reduced distinctly to 44 at 3 apple orchards. When the provinces were compared with one another, the number of diseased trees in Gyeongbuk, Chungnam, Chungbuk, and Jeonbuk has increased much more than that of the past years. All the data from provinces such as Gyeonggi, Gangwon, Jeonnam, and Gyeongnam were not comparable due to our/their limited data.

Lee et al. (2006) reported the occurrence degree by using the plus signs as in the parenthesis $(+$, rare; ++ , frequent; +++ , ubiquitous) for the soil-borne diseases which had occurred all over the country in 1992-2000. The incidence degree for Phytophthora rot was rare (+) across the country. The occurrences for violet and white root rot were frequent $(++)$ at all provinces, except for Gyeonggi and Gangwon. Although our survey could not be directly compared with the report above, it showed that the incidence degree of Phytophthora rot had increased from rare (+) to frequent (++)ubiquitous $(+++)$, and that of white root rot had decreased to rare (+) from frequent severity (++).

Most recently, Lee et al. (2016) reported that 3,350 apple trees had been infected by soil-borne diseases at 24 apple orchards in Chungbuk province from 2013 to 2015. Among these infected apple trees, the number of apple trees dis- eased by Phytophthora rot was 2,015 (60.2\%) at 14 orchards, that of by violet root rot was 1,085 (32.4\%) at 5 orchards, and that of by white root rot was $250(7.5 \%)$ at 5 orchards. Our data represent additional pathogenesis apple trees in Chungbuk, compared to the previous report (Lee et al., 2016). Therefore, our data reveal that the number of dieback trees in Chungbuk had been at least 5,025 at 46 apple orchards in 2013-2019 (sum of both 3,350 at 24 orchards in 2013-2015 and 1,675 at 22 orchards in 2016-2019).

The causes of recent increase by soil-borne diseases in apple orchards across the country were attributed to the poor vertical drainage like clay soil, the decreased effect of the underdrain brought about by heavy moisture at apple orchards (Jung et al., 2010, 2012; Kim et al., 2001) and increased concentration of soil-borne fungal pathogens (Gur et al., 1972, 1976b; Jee et al., 2000; Park and Oh, 2001), the various stresses (Bowen, 1991; Park and Oh, 2001; Sachs et al., 1980; Skaggs et al., 1982), the high temperature disorder (Gur et al., 1972, 1976b; Park and Oh, 2001) caused by the rising temperature of underground (Gur et al., 1976a; Sagong et al., 2011) along with global warming.

Temperature, rainfall, and soil chemical property are important factors in the pathogenesis of Phytophthora rot. Tsao and Garber (1960) reported that Phytophthora rot frequently occurred in high soil humidity and prolonged flood and was more common in clay soil than in sandy soil. Also, Babadoost (1988) reported that Phytophthora rot occurred mainly in late August to early October when the soil was wet and the temperature was around $13-21^{\circ} \mathrm{C}$, and if the temperature were higher than the previous year or rainfall days was more than that, there would be a very high risk of its occurrence. The influence of soil chemical property on the occurrence of Phytophthora rot was so diverse that it was difficult to draw a consistent conclusion, but the field used with complex fertilizers had higher pathogenesis than unused field, and its pathogenesis rate was much higher in the field that applied more than twice as the standard quantity (Schmitthenner and Canaday, 1983). Therefore, we suggest that infection by Phytophthora rot would be reduced by applying of standard quantity for fertilizers at apple orchards in Chungbuk, Jeonbuk, and Gyeongbuk provinces.

The disease incidence rate of the violet root rot was relatively higher in newly made (under 10 years) apple orchard, while the reverse was observed in the white root rot. The 
degree of dwarfishness of the rootstock was positively related to the infection rate of the violet root rot, but not to the white root rot. The violet root rot occurred the most in clay loam soil and the white root rot occurred the most in sandy loam soil (Lee et al., 1995). Considering that most of Korea's surface soil properties were from sandy loam soil to clay loam soil (Korean Soil Information System, http://soil.rda. go.kr), white root rot would be confronted with danger to occur across the country, in spite of occurrence in Chungbuk and Gyeongbuk province only.

Recently, Lee et al. (2017) reported the correlation between dieback ratio and soil chemical property in apple orchards infected by soil-borne diseases. The dieback ratio by violet root rot and by white root rot showed significantly positive correlation with $\mathrm{Ca}$ and available $\mathrm{P}_{2} \mathrm{O}_{5}$ content in soil, respectively. Whereas, that by Phytophthora rot was not significant. Like this, correlation analysis between dieback ratio induced by soil-borne diseases and soil chemical property on a national scale would be useful to strategy for future disease control.

In conclusion, our survey has been conducted on much more apple trees and orchards than those of the past reports, and it possible to represent the mixed infection in South Korea. Since the dieback symptom resulting from soil-borne fungal pathogens in apple trees are not easily to be controlled by the fungicides, it is essential to establish a comprehensive and effective control method, and clarify the dieback causes based on the understanding of cultivation characteristics and soil environment for the infected apple orchards throughout the country.

\section{Conflicts of Interest}

No potential conflict of interest relevant to this article was reported.

\section{Acknowledgments}

This survey was carried out with the support of the Chungcheongbuk-do Agricultural Research and Extension Services, funded by the provincial government of Chungcheongbuk-do, the Republic of Korea. We extend our special thanks to Dr. Moon-Soo, Hwang for grammatical editing of this manuscript.

\section{References}

Babadoost, M. 1988. Phytophthora Collar Rot of Apple. Report on Plant Disease, No. 812. University of Illinois Extension, Urbana, IL, USA. 4 pp.

Bowen, G. D. 1991. Soil temperature, root growth and plant function. In: Plant Root: The Hidden Half, eds. by Y. Waisel, A. Eshel and U. Kafkafi, pp. 309-329. Marcel Dekker, Inc., New York, NY, USA.

Gur, A., Bravdo, B. and Hepner, J. 1976a. The influence of root temperature on apple trees. III. The effect on photosynthesis and water balance. J. Hortic. Sci. 51: 203-210.

Gur, A., Bravdo, B. and Mizrahi, Y. 1972. Physiological responses of apple trees to supraoptimal root temperature. Physiol. Plant. 27: 130-138.

Gur, A., Hepner, J. and Mizrahi, Y. 1976b. The influence of root temperature on apple trees. I. Growth responses related to the application of potassium fertilizer. J. Hortic. Sci. 51: 181-193.

Hanlin, R. T. 1990. Illustrated Genera of Ascomycetes. American Phytopathological Society, St. Paul, MN, USA. 263 pp.

Jee, H.-J., Cho, W.-D. and Kim, C.-H. 2000. Phytophthora Diseases in Korea. Rural Development Administration, Suwon, Korea. 226 pp. (In Korean)

Jee, H.-J., Cho, W.-D. and Kim, W.-G. 1997. Phytophthora diseases of apple in Korea: I. Occurrence of a destructive collar rot caused by P. cactorum. Korean J. Plant Pathol. 13: 139-144.

Jee, H.-J., Cho, W.-D., Nam, K.-W. and Park, Y.-S. 2001. Outbreak of Phytophthora rot on pear under environmental conditions favorable to the disease. Plant Pathol. J. 17: 231-235.

Jung, K.-Y., Yun, E.-S., Park, C.-Y., Hwang, J.-B., Choi, Y.-D., Jeon, S.-H. et al. 2012. Variation of soil physical characteristics by drainage improvement in poorly drained sloping paddy field. Korean J. Soil Sci. Fertil. 45: 704-710. (In Korean)

Jung, K.-Y., Yun, E.-S., Park, K.-D. and Park, C.-Y. 2010. Evaluation of drainage improvement effect using geostatistical analysis in poorly drained sloping paddy soil. Korean J. Soil Sci. Fertil. 43: 804-811. (In Korean)

Kim, L.-Y., Cho, H.-J., Hyun, B.-K. and Park, W.-P. 2001. Effects of physical improvement practices at plastic film house soil. Korean J. Soil Sci. Fertil. 34: 92-97. (In Korean)

Lee, D.-H., Choi, K.-H. and Uhm, J.-Y. 2009. Cytochalasin E production by Rosellinia necatrix and its pathogenicity on apple. Res. Plant Dis. 15: 46-50. (In Korean)

Lee, D. H., Lee, S. W., Choi, K. H., Kim, D. A. and Uhm, J. Y. 2006. Survey on the occurrence of apple diseases in Korea from 1992 to 2000. Plant Pathol. J. 22: 375-380.

Lee, S. B., Chung, B. K., Jang, H. I., Kim, K. H. and Choi, Y. M. 1995. Incidence of soil-borne diseases in apple orchards in Korea. Korean J. Plant Pathol. 11: 132-138. (In Korean)

Lee, S.-H., Kwon, Y., Shin, H., Kim, I.-J., Nam, S.-Y., Hong, E. Y. et al. 2016. Dieback of apple tree by major soil borne diseases in 
Chungbuk province from 2013 to 2015. Res. Plant Dis. 22: 198201. (In Korean)

Lee, S.-H., Kwon, Y., Shin, H., Kim, I.-J., Nam, S.-Y., Hong, E. Y. et al. 2017. Correlation between the dieback ratio and cultivation environment for apple orchards infected by soil-borne diseases in Chungbuk province. Res. Plant Dis. 23: 49-55. (In Korean)

Park, J.-M. and Oh, S.-D. 2001. Effect of root zone temperature in orchard on the air and the chemical properties of the soil, and the growth of 'Fuji' apple trees. Korean J. Soil Sci. Fertil. 34: 380-386. (In Korean)

Rural Development Administration, National Institute of Agricultural Science and Technology. 1993. Compendium of Fruit Tree Diseases with Colour Plates. Rural Development Administration, Suwon, Korea. 286 pp. (In Korean)

Sachs, M. M., Freeling, M. and Okimoto, R. 1980. The anaerobic proteins of maize. Cell 20: 761-767.

Sagong, D.-H., Lee, S.-J., Han, S.-G. and Yoon, T.-M. 2011. The influence of materials for surface mulching on soil temperature and vegetative growth of apple nursery trees. Korean J. Agric. For.
Meterol. 13: 1-9. (In Korean)

Schmitthenner, A. F. and Canaday, C. H. 1983. Role of chemical factors in the development of Phytophthora diseases. In: Phytophthora: Its Biology, Taxonomy, Ecology, and Pathology, eds. by D. C. Erwin, S. Bartnicki-García and P. H. Tsao, pp. 189-196. American Phytopathological Society, St. Paul, MN, USA.

Sivanesan, A. and Holliday, P. 1972. Rosellinia necatrix. CMI. Descr. Pathog. Fungi Bacteria 352: 1-2.

Skaggs, R. W., Hardjoamidjojo, S., Wiser, E. H. and Hiler, E. A. 1982. Simulation of crop response to surface and subsurface drainage systems. Trans. ASAE 25: 1673-1678.

The Korean Society of Plant Pathology. 2009. List of Plant Disease in Korea. 5th ed. The Korean Society of Plant Pathology, Suwon, Korea. 859 pp. (In Korean)

Tsao, P. H. and Garber, M. J. 1960. Methods of soil infestation, watering, and assessing the degree of root infection for greenhouse in situ ecological studies with citrus Phytophthoras. Plant Dis. Rep. 44: 710-715. 